\title{
An isotope dilution mass spectrometric measurement procedure has the potential of being a very good reference measurement procedure, but is not a "definitive" one
}

\author{
Paul De Bièvre
}

Published online: 4 April 2010

(C) Springer-Verlag 2010

The term "definitive methods" to describe isotope dilution mass spectrometry (IDMS) as a powerful measurement procedure [1], started to be recognized in the seventies [29]. It was inspired by the at that time impressive achievements in analytical measurement in chemistry at the isotope mass spectrometry laboratories of the National Bureau of Standards (NBS) in Gaithersburg (US) and the Central Bureau for Nuclear Measurements (CBNM) in Geel (EC). Applying the measurement principle of isotope dilution and combining it with isotope mass spectrometry, enabled to certify "reference values" with drastically reduced measurement uncertainties.

Described in the simplest form, the measurement of a number $N\left({ }^{i} \mathrm{E}\right)$ of atoms of an isotope ${ }^{i} \mathrm{E}$ of an element $\mathrm{E}$, can be performed by adding a known number of atoms $N\left({ }^{j} \mathrm{E}\right)$ of another isotope ${ }^{j} \mathrm{E}$ (= a "spike") of the same element, and measuring the number-ratio $N\left({ }^{i} \mathrm{E}\right) / N\left({ }^{j} \mathrm{E}\right)$.

[A similar approach had long been used by analysts in classical chemistry. It is called the "standard addition method". An unknown number $N\left({ }_{i} \mathrm{E}\right)$ of atoms of an element ${ }_{i} \mathrm{E}$ is measured by adding a known number of atoms $N\left({ }_{j} \mathrm{E}\right)$ of atoms of another element ${ }_{j} \mathrm{E}$ and measuring the number-ratio $N\left({ }_{i} \mathrm{E}\right) / N\left({ }_{j} \mathrm{E}\right)$.]

This number-ratio measurement is independent of chemical effects since isotopes of the same element have the same chemical properties. The approach consists of selecting a major abundant isotope ${ }^{i} \mathrm{E}$ of the element $\mathrm{E}$ in a sample and selecting another-but also major abundantisotope ${ }^{j} \mathrm{E}$ of $\mathrm{E}$ in the "spike". Since in most cases, the aim of IDMS is not to measure an isotope amount (which can

P. De Bièvre $(\bowtie)$

Kasterlee, Belgium

e-mail: paul.de.bievre@skynet.be be done) but an element amount, the minor-abundant isotopes must be taken into account in the unknown sample as well as in the spike. In the spike this is done by measuring them through a number-ratio measurement relative to the major-abundant isotope ${ }^{j} \mathrm{E}$. Similarly, in the sample, this is done by measuring the minor-abundant isotopes through a number-ratio measurement relative to the major-abundant isotope ${ }^{i} \mathrm{E}$ [10-12].

Thus the traditional measurement of a number-ratio of specified atomic entities (in the "standard addition method") is replaced by the measurement of a numberratio of specified isotopic entities (in IDMS). Since chemical, i.e. element-dependent effects, play their full role in any element-to-element ratio measurement, this ratio is far more dependent on chemical systematic effects (which are different for different elements) than an isotope-toisotope number-ratio where the chemical effects play the same role, and hence are cancelled out in the measurement of the number-ratio of isotopic atoms: the same systematic effects which will influence proportionally the nominator of the number-ratio, will also influence the corresponding denominator of that number-ratio. The effects in nominator and denominator will cancel because they are identical (they relate to the same element).

[The small systematic effect due to mass discrimination is not discussed here because it is small relative to chemical affects.]

The result is that both precision and accuracy of the measured ratio value is very much improved. In GUM language, it reduces the overall measurement uncertainty of that measurement result.

This drastic improvement of the quality of measurement gave rise to the creation of the concept "definitive method": suddenly a very good reference measurement procedure became available yielding results with much 
smaller measurement uncertainty. A very useful achievement indeed.

However, there is always a measurement uncertainty associated with a measurement albeit (much) smaller than previous uncertainties. But, as long as a measurement is involved, a measurement uncertainty will always be there.

A measurement procedure (previously called "measurement method") and its ensuing measurement result can never be "definitive".

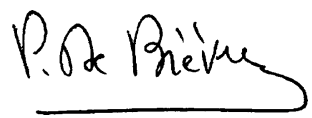

Paul De Bièvre

Editor-in-Chief

By the way: looking for some justification for Metrology in Chemistry?

By monitoring measurement results for cholesterol in human serum, the USA annually saves USD 100000000 in health care cost.

("Footprint of the Meter", Nationaal Meetinstituut, Delft (NL), (1999))

\section{References}

1. BIPM, IEC, IFCC, ILAC, IUPAC, IUPAP, ISO, OIML (2008) The international vocabulary of metrology-basic and general concepts and associated terms (VIM), 3rd edn. JCGM 200:2008, entry 2.6. http://www.bipm.org/en/publications/guides/vim.html

2. De Bièvre P, Stable Isotope Dilution (1971) A possible tool for the analytical chemistry of noble metals. In: "Méthodes analytiques nucléaires dans la production et l'utilisation industrielle des métaux précieux". EURISOTOP Report 71, Commission of the European Communities, Brussels

3. Cali JP, Mandel J, Moore L (1972) A referee method for the determination of calcium in serum. NBS Special Publication, NIST, Gaithersburg, pp 260-36

4. Young DS (1974) Z Klin Chem Klin Biochem 12:560

5. Cali JP (1975) Reference materials in clinical chemistry, clinical laboratory developments. Federation Proceedings 34:2123-2126

6. De Bièvre P (1976) Accurate isotope ratio mass spectrometry: some problems and possibilities (in Adv Mass Spectrom). In: Proceedings 7 th international mass spectrometry conference, Firenze. Heyden \& Son Ltd, London, pp 395-447

7. Cali JP, Reed WR (1976) The role of the national bureau of standards, standard reference materials in accurate trace analysis. In: Accuracy in trace analysis. NBS Special Publication 422, vol I. pp 41-63

8. Uriano A, Gravatt CC (1977) The role of reference materials and reference methods in chemical analysis. In: CRC critical reviews in analytical chemistry, Oct. pp 361-411

9. De Bièvre $P$ (1990) Isotope dilution mass spectrometry: what can it contribute to accuracy in trace analysis? Fresenius J Anal Chem 337:766-771

10. De Bièvre P (1993) Isotope dilution mass spectrometry as a primary method of analysis. Anal Proc 30:328-333

11. De Bièvre P (1994) Isotope dilution mass spectrometry, chap 8 . In: Herber RFM, Stoeppler M (eds) Trace element analysis in biological specimens. Elsevier, Amsterdam, pp 169-183

12. De Bièvre P, Peiser HS (1997) Basic equations and uncertainties in isotope-dilution mass spectrometry for traceability to SI of values obtained by this primary method. Fresenius $\mathbf{J}$ Anal Chem 359:523-525 